\title{
Davide Vago, Proust en couleur
}

\section{Geneviève Henrot Sostero}

\section{(2) OpenEdition}

\section{Journals}

Édition électronique

URL : http://journals.openedition.org/studifrancesi/2262

DOI : 10.4000/studifrancesi.2262

ISSN : 2427-5856

\section{Éditeur}

Rosenberg \& Sellier

\section{Édition imprimée}

Date de publication : 1 avril 2014

Pagination : 180

ISSN : 0039-2944

\section{Référence électronique}

Geneviève Henrot Sostero, «Davide Vago, Proust en couleur », Studi Francesi [En ligne], 172 (LVIII | I) |

2014, mis en ligne le 01 avril 2014, consulté le 18 septembre 2020. URL : http://

journals.openedition.org/studifrancesi/2262 ; DOI : https://doi.org/10.4000/studifrancesi.2262

Ce document a été généré automatiquement le 18 septembre 2020.

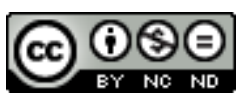

Studi Francesi è distribuita con Licenza Creative Commons Attribuzione - Non commerciale - Non opere derivate 4.0 Internazionale. 


\title{
Davide Vago, Proust en couleur
}

\author{
Geneviève Henrot Sostero
}

\section{RÉFÉRENCE}

DAVIDE VAGO, Proust en couleur, Paris, Champion, 2012 («Recherches proustiennes», 23),

pp. 274.

1 Le thème de la couleur n'avait plus fait l'objet d'une réflexion d'ensemble depuis la monographie d'Allan A. Pasco (The Color Keys to "À la recherche du temps perdu", Genève, Droz, 1976). Après plus de trente ans, il méritait donc une reprise à la lumière de la conscience critique contemporaine.

2 La première partie de l'ouvrage est consacrée au fond théorique et philosophique qui sous-tend la lecture critique. Elle place la perception chromatique au croisement de plusieurs disciplines: science (Chevreul), philosophie (Séailles, Merleau-Ponty), critique d'art (Baudelaire, les Impressionnistes), photographie.

3 La seconde partie du livre met en lumière une «théorie de la couleur» commune à la Recherche et aux autres œuvres de Proust. Les différents aspects du chromatisme proustien y sont décrits dans une marche qui progresse du franchement visible (lumière, matière et formes) au fondu (avec les autres sens: la synesthésie et ses fonctions), au symbolique: elle s'attache à la rencontre de la perception et de la connaissance des arts picturaux (par l'ekphrasis), littéraires (par l'intertextualité sous toutes ses formes), couturiers (la mode et sa fonction sociale). Mais la perception chromatique se pose également comme essence de la temporalité, en ce qu'elle scande et colore singulièrement chaque étape de la maturation artistique du narrateur: elle accompagne et introduit sur le mode visuel le progressif amalgame du style, son «vernis de maitre». Il est frappant d'observer combien l'expression de la couleur semble évoluer d'une franche lexicalisation (relativement docile aux relevés numériques et aux statistiques) vers une sémantisation inédite, diffuse, impalpable, subliminale, confiée aux inférences et afférences sémiques qui reposent elles-mêmes sur une connaissance partagée du monde: si la mer de Balbec a d'abord été décrite 
comme verte et bleue comme une queue de paon, le lecteur proustien garde en mémoire cette évocation, mémoire sur laquelle l'écrivain compte sans doute lorsqu'ensuite il choisit de faire l'économie des adjectifs de couleur; mais la "couleur» n'en est pas moins présente dans l'imagerie référentielle que se crée le lecteur. Il serait intéressant de vérifier plus systématiquement cette hypothèse stylistique d'un «abandon» des termes de couleur en tenant rigoureusement compte des étapes de rédaction de la Recherche (qui comme on sait diffèrent grandement de la chronologie diégétique et éditoriale de l'œuvre) et du comportement génétique du thème chromatique.

4 Clôturent le volume une «Annexe de statistique», une «Bibliographie» très nourrie, les «Index» de rigueur (noms de personnes, personnages, lieux, thèmes et notions). 